\title{
Psychological quality of life and its association with academic employability skills among newly- registered students from three European faculties
}

\author{
Michèle Baumann ${ }^{1 *}$, Ion Ionescu ${ }^{2}$ and Nearkasen $\mathrm{Chau}^{3}$
}

\begin{abstract}
Background: In accord with new European university reforms initiated by the Bologna Process, our objectives were to assess psychological quality of life (QoL) and to analyse its associations with academic employability skills (AES) among students from the Faculty of Language, Literature, Humanities, Arts and Education, Walferdange Luxembourg (F1, mostly vocational/applied courses); the Faculty of Social and Human Sciences, Liege, Belgium (F2, mainly general courses); and the Faculty of Social Work, lasi, Romania (F3, mainly vocational/professional courses).

Method: Students who redoubled or who had studied at other universities were excluded. 355 newly-registered first-year students ( 145 from F1, 125 from F2, and 85 from F3) were invited to complete an online questionnaire (in French, German, English or Romanian) covering socioeconomic data, the AES scale and the QoL-psychological, QoL-social relationships and QoL-environment subscales as measured with the World Health Organisation Quality of Life short-form (WHOQoL-BREF) questionnaire. Analyses included multiple regressions with interactions.

Results: QoL-psychological, QoL-social relationships and QoL-environment' scores were highest in F1 (Luxembourg), and the QoL-psychological score in F2 (Belgium) was the lower. AES score was higher in F1 than in F3 (Romania). A positive link was found between QoL-psychological and AES for F1 (correlation coefficient 0.29, p $<0.01$ ) and F3 (correlation coefficient 0.30, p < 0.05), but the association was negative for F2 (correlation coefficient $-0.25, p<0.01$ ). QoL-psychological correlated positively with QoL-social relationships (regression coefficient 0.31, $p<0.001$ ) and QoL-environment (regression coefficient 0.35, p $<0.001$ ).

Conclusions: Psychological quality of life is associated with acquisition of skills that increase employability from the faculties offering vocational/applied/professional courses in Luxembourg and Romania, but not their academically orientated Belgian counterparts. In the context of developing a European Higher Educational Area, these measurements are major indicators that can be used as a guide to promoting programs geared towards counseling, improvement of the social environment, and services to assist with university work and facilitate achievement of future professional projects.
\end{abstract}

Keywords: students WHOQoL-BREF, QoL-psychological, employability, academic skills, QoL-environmental, QoLsocial relationships

\section{Background}

There are 16 million university students in Europe, with an annual growth rate of over $2 \%$ [1]. Data from the 'Organisation de coopération et de développement économiques' (OCDE) show that $31 \%$ of students quit university dramatically without a diploma, i.e. having failed to

\footnotetext{
* Correspondence: michele.baumann@uni.lu

${ }^{1}$ INSIDE research unit, University of Luxembourg, Walferdange L-7201

Luxembourg

Full list of author information is available at the end of the article
}

achieve their educational/professional projects [2]. This occurs during the early university years, when young people are establishing, testing and adjusting new psychological identities [3]. However, according to the Organisation Economic Cooperation and Development's (OECD) data the proportion of university students who do not take their first diploma varies widely between countries: $40 \%$ in the United States, Mexico, New Zealand and Sweden, under 25\% in Belgium, Korea, Denmark, Spain, France and Japan [2].

\section{Ciomed Central}

() 2011 Baumann et al; licensee BioMed Central Ltd. This is an Open Access article distributed under the terms of the Creative Commons Attribution License (http://creativecommons.org/licenses/by/2.0), which permits unrestricted use, distribution, and reproduction in any medium, provided the original work is properly cited. 
University students are exposed to mental difficulties related to young adulthood and have also to face with mental and social issues related to students' life [4]. It is well known that young adults experience psychological disorders, depression, unhealthy behaviours, and suicidal ideation due to their social situation and living conditions [5,6]. As students, many of them also face changes in living conditions, lifestyle and environment [7], while dealing with issues around financial support, social interaction, parental status and loneliness [8]. Many students live far from home, making them vulnerable to starting smoking and excessive alcohol consumption [9]. Today, students are expected to be competitive, adding to the pressure and leading to much more stress [10]. These issues may cause insomnia, anxiety, depression, dietary disorders and behavioural consequences $[11,12]$ with an impact on academic achievement $[13,14]$. They may also generate coping strategies [15] leading to somatic disorders and violent behaviour [16]. These concerns call for a better integration of education and health care [17]. One Swedish study found that students appear to have a QoL that is lower than that of young workers of the same age [18] and is associated with academic failure, job difficulties, and diverse social outcomes later in life [19]. There is now a pressing need to explore the implications of social relationships, environment and academic employability skills for psychological issues among newly-registered students. Ultimately, interventions should be designed and evaluated, and then the most promising interventions should be implemented on a large scale.

Because social, environmental and economic contexts may vary greatly between countries it is of interest to assess whether those issues differ between universities. Three sites are considered here: in Luxemburg, Belgium and Romania. Although the Grand-duchy of Luxembourg is the smallest country in Europe (506.000 people), it is a multicultural and a multi-language society (about 170 nationalities), and the University of Luxembourg is the youngest in Europe (created in 2003). A cross-university survey “The Students' Quality of Life and Employability Skills (SQALES)", initiated by the research unit INSIDE [20] was presented to the network of the Foundation of European Regions for Research in Education and Training [21]. Two European public institutions expressed an interest in similar research; one in Liege (Belgium) and the other in Iasi (Romania). The aims of the SQALES project are: 1) to meet the recommendations adopted at Bergen (2005), under the Bologna Process, that call on universities for high levels of competition and production; and 2) to help all those involved in university education to produce guidance and advice taking some account of existing facilities (health promotion activities, employability workshops, counseling services, support for university work, student union welfare officers) and opportunities for further development [22]. In a similar vein, the Human Resources Development Canada Department of Research has created a self-rated questionnaire for university students to gauge how convinced they are of having the academic skills needed for employment according to the following dimensions: communication, interpersonal relationships, and capacity for innovation [23].

Investigating university students in Eastern and Western Europe is of interest because of disparities in health and socioeconomic issues. Compared to their Western European counterparts, Eastern Europeans have a lower prevalence of depression, weaker social support and poorer health [24]. A disproportionate number of central and eastern European students exhibit low levels of satisfaction with life, and they are more likely to believe that chance plays a major role in life achievement [25]. Psychological health, its determinants and comparisons between European countries are receiving increased attention [26,27]. Recognising psychological QoL as an issue and monitoring its fluctuation is an essential precondition to providing appropriate services and assistance to support students at university. It is agreed that a student who has a sense of well-being is more likely to achieve his/her goals, complete training, and enter the world of work. This is a major ethical issue, because we are responsible for our young people whom we ask to take up the socio-economic challenges of the current crisis. Therefore, activities with beneficial effects on mental health and well-being promote effective learning [28]. In this perspective, there is a real need for universities to evaluate the psychological difficulties of students.

Past research has shown that the WHOQoL-BREF is a relevant, reliable and valid cross-cultural scale appropriately used to measure the following four domains: physical, psychological, social relationships and environment [26]. It is the short-form of the World Health Organisation Quality of Life questionnaire. The World Health Organisation defines Quality of Life (QoL) as "the individual's perception of his/her position in life in the context of the culture and value systems in which he/she lives and in relation to his/her goals, expectations, standards, and concerns" [26]. The cross-cultural nature of the WHOQoL-BREF should make it appropriate as a means of measuring psychological status, social relationships and environment. In the European Union, QoL is considered a high social and public health policy priority that reflects wider public concerns [27]. In 2008, the European Pact signed in Brussels recognised that the mental health and well-being of the population play essential roles in the economic and social success of the Union [29]. Studies have confirmed the reliability and validity of the WHOQoL-BREF among students in 
various countries [30-34]. One investigation showed that a health enhancement program improved the psychological domain among medical students in Australia [30]. A high correlation was found between the psychological domain and existential well-being among social sciences students in Brazil [35]. QoL is associated with loneliness among students of health services in Turkey [36]. The psychological domain was found to be related to pparental rearing among university students in Brazil [37]. Few studies have examined the links between QoL globally and in its four domains [38]. We did not focus here on the physical domain.

The objectives of this study were to assess the QoLpsychological and to analyse its association with academic employability skills (AES), and other relevant factors among students at three European faculties: the Faculty of Language and Literature, Humanities, Arts and Education (F1), Walferdange, Luxembourg, which offers mainly vocational/applied courses; the Faculty of Social and Human Sciences (F2), Liege, Belgium, which offers mainly general/academic courses; and the Faculty of Social Work (F3), Iasi, Romania, offering mainly vocational/professional courses. Additionally, we addressed the question of whether there is a difference between students in vocational/applied and general/liberal courses/studies.

\section{Methods}

Population

A total of 355 first year newly-registered students in social sciences were invited to participate in the survey: 145 from Luxembourg (F1), 125 from Belgium (F2), and 85 from Romania (F3). Students who redoubled or who had studied at other universities were excluded.

\section{Ethics}

The ethical research committees of each faculty approved the study protocol in advance, and informed consent was obtained from all respondents. Representatives of students' associations and a member of the research team provided information about the goals of the survey. The Study Directors considered the online questionnaire more appropriate than "asking students to fill in the survey during courses". This is the usual procedure in student research, but its value is open to question, particularly if the objective is to systematically collect data free of potential bias due to interaction between university staff and students.

\section{Procedure}

Four months after the beginning of the academic year, the research team (with the cooperation of representatives of students' associations) presented information about the study and its aims and the students were assured that refusal to participate in the survey would have no effect on their academic standing. Students were asked to complete an online self-reported questionnaire via an anonymous email address in the language of their choice.

\section{Data collected}

Three groups of variables were collected:

a) The dependent variable QoL-psychological was measured using the WHOQOL-BREF questionnaire (QoL-physical was not considered in this survey) [26]. The psychological subscale consists of six items on a five-point scale: (a) Bodily image and appearance, (b) Negative feelings, (c) Positive feelings, (d) Self-esteem, (e) Spirituality / Religion / Personal beliefs, and (f) Thinking, learning, memory and concentration. It has been validated in the languages used for the investigation: German [39], French [40], English and Romanian [41]. The scale is easy to administer, to complete and to score (the higher the score, the higher the perceived QoL-psychological). The internal consistency (Cronbach's alpha) coefficient was 0.77 among all students and similar to that of other studies [34,42].

b) The variable Academic Employability Skills (AES) was assessed using six items measuring students' perceptions of their competencies or capacities to write, think critically, solve problems, work effectively with others, lead others, and use new technology. Each student was invited to estimate his or her level on a Likert scale of 1 (not very good) to 4 (excellent). The Cronbach's alpha coefficient was 0.76 among all students. The higher the score, the higher the perceived acquisition of AES. English and French versions are available [23]. The German and Romanian versions were translated and back-translated by a team comprising a language-expert specialist in public health and a professor specialist in employability.

c) Other factors

- The importance of going to university was assessed on a four-point scale from "very important", "important", "little important" and "not important" step. The Cronbach's alpha coefficient was 0.52 . The higher the score, the higher the perceived importance.

- The QoL-social relationships and QoL-environment domains were measured with the subscales of the WHOQOL-BREF [26]. QoL-social relationships included three five-point scale items: (a) Personal relationships, (b) Social support and (c) Sexual activity). QoL-environment included eight five-point scale items: (a) Financial resources, (b) Freedom, physical safety and security, (c) Health and social care: accessibility and quality, (d) Home environment, (e) Opportunities for acquiring new information and skills, (f) Participation in and opportunities for recreation / leisure activities, (g) Physical environment (pollution / noise / traffic / climate) and 
(h) Transport. They were studied as potential factors related to the QoL-psychological. Their Cronbach's alpha coefficients were 0.64 and 0.77 respectively among all students and were similar to those of other studies $[34,42]$. The higher the score, the higher the perceived QoL.

- The socio-demographic characteristics: age, sex (female/male), level of education of the father and the mother (1: End of compulsory studies; 2: Sixth form college diploma NVQ equivalent; 3: 12th grade diploma or 'A' level in Technical or professional studies; 4: University, college (higher education) diploma BTEC HND equivalent or first degree; 5: University, or specialised school diploma (higher education) Master or Doctorate / Engineer equivalent) and their professional status (manual worker / employee / senior officer).

\section{Statistical analysis}

First, the three groups of respondent students were compared for each variable using Chi-square tests and Student's t-tests. Then multiple regression models were used in two steps: (1) we performed the regression model for the WHOQOL-BREF-psychological subscale in terms of socio-demographic characteristics and the faculty, including their interaction terms by retaining only the variables/interaction terms with $\mathrm{p}<0.10$; (2) we added to the previous model AES, QoL-social relationships, QoL-environment and their interaction terms also by retaining only the variables/interaction terms with $\mathrm{p}<0.10$.

\section{Results}

Among the 355 newly-registered students contacted, 236 (66\%) participated: 85 from Luxembourg (participation rate 55\%), 82 from Belgium (participation rate 66\%) and 69 from Romania (participation rate 81\%).

The socio-demographic characteristics of the subjects are shown in Table 1 . Samples were predominantly female: $75.3 \%$ of F1, $67.1 \%$ of F2, and $89.9 \%$ of F3. F2 was the youngest sample (mean age $(\mathrm{SD})=18.5(0.87)$ years), compared with F3 (mean age $(\mathrm{SD})=19.1(0.37)$ ), and F1 (mean age $(\mathrm{SD})=21.2(3.31)$ ). The F1 students entered the University of Luxembourg one year later, which explains the differences in age. The highest education level among fathers and mothers (university/ higher education / BTEC HND) was in F2. Employees predominated in F1 and F2 and manual workers in F3. Going to university was 'very important' for more F3 (78.3\%) than F1 (55.3\%) and F2 (30.9\%).

As shown in Table 2, we found that QoL-psychological, AES, QoL-social relationships and QoL-environment differed significantly between the three faculties. All scores were higher in F1: psychological (74.4 vs. 63.7 in F2), social relationships (75.3 vs. 65.2 in F3), and environment (71.7 vs. 56.3 in F3). The same was true for the AES (77.7 vs. 68.2 in F2).

Table 3 shows the relationships between WHOQOLBREF psychological subscale and socio-demographic characteristics, AES, QoL-social relationships and QoLenvironment, for each faculty separately. QoL-psychological was not significantly linked with any socio-demographic factor other than the father's educational level in F3. For all faculties, QoL-psychological correlated positively with QoL-social relationships and QoL-environment. QoL-psychological correlated positively with the AES for vocational/applied courses at the faculties F1 (correlation coefficient 0.288, p = 0.009) and F3 (correlation coefficient $0.297, \mathrm{p}=.015$ ), but the link was negative for general/academic courses at F2 (correlation coefficient $-0.255, \mathrm{p}=0.03$ ). These differences concerned all items of the AES, but principally the three items problem solving, team working, and supervision/ direction of others, which were associated with QoLpsychological.

Table 4 shows the results obtained with the multiple regression model for WHOQOL-BREF-psychological subscale in terms of socio-demographic factors, AES, QoL-social relationships and QoL-environment subscales. No socio-demographic factor had a significant effect at the $10 \%$ level, whether or not the model included interaction terms with the faculties. There was a highly significant effect for the faculty, as QoL-psychological was higher for F1 and F3 than for F2 (regression coefficient -5.03 vs. about 2.5 for F1 and F3). More specifically, the AES related positively to QoL-psychological for F1 and F3, but negatively for F2. QoL-Psychological correlated positively with QoL-social relationships (regression coefficient 0.31, p < 0.001) and QoL-environmental (regression coefficient 0.35, p $<0.001$ ).

\section{Discussion}

This study improves our understanding of the associations between the psychological quality of life, the social and environmental contexts, and the acquisition of academic employability skills among social sciences students. QoL-psychological, academic employability skills, QoL-social relationships and QoL-environment (living conditions and lifestyles on campus) differed markedly between the students from the faculties in Luxembourg (F1), Belgium (F2) and Romania (F3). QoL-psychological was positively and similarly associated with QoL-social relationships and QoL-environmental for the three faculties, and was related to the perceived importance of going to university and socio-demographic factors (professional status, level of education of the parents - all of which are major factors in creating social inequalities in health [43]) at all faculties. The association between QoL-psychological and academic employability skills 
Table 1 Socio-demographic characteristics of respondents: mean (SD) or \%

\begin{tabular}{|c|c|c|c|c|c|}
\hline & & F1 (Luxembourg) N = 85 & F2 (Belgium) $\mathrm{N}=82$ & F3 (Romania) N = 69 & $\mathrm{p}$-value \\
\hline Age & & $21.2(3.31)$ & $18.5(0.87)$ & $19.1(0.37)$ & 0.000 \\
\hline \multirow[t]{2}{*}{ Sex } & Female & 75.3 & 67.1 & 89.9 & 0.004 \\
\hline & Male & 24.7 & 32.9 & 10.1 & \\
\hline \multirow[t]{5}{*}{ Father's educational level } & 1 & 15.9 & 10.9 & 23.2 & 0.000 \\
\hline & 2 & 34.1 & 14.1 & 42.0 & \\
\hline & 3 & 19.5 & 17.2 & 21.7 & \\
\hline & 4 & 14.6 & 15.6 & 8.7 & \\
\hline & 5 & 15.9 & 42.2 & 4.3 & \\
\hline \multirow[t]{5}{*}{ Mother's Educational level } & 1 & 17.1 & 10.3 & 26.1 & 0.000 \\
\hline & 2 & 25.6 & 5.9 & 33.3 & \\
\hline & 3 & 28.0 & 22.1 & 26.1 & \\
\hline & 4 & 17.1 & 42.6 & 5.8 & \\
\hline & 5 & 12.2 & 19.1 & 8.7 & \\
\hline \multirow[t]{3}{*}{ Father's professional status } & Manual worker & 19.5 & 15.0 & 51.5 & 0.000 \\
\hline & Employee & 51.2 & 40.0 & 22.1 & \\
\hline & Senior officer & 29.3 & 45.0 & 26.5 & \\
\hline \multirow[t]{3}{*}{ Mother's professional status } & Manual worker & 17.1 & 5.1 & 49.3 & 0.000 \\
\hline & Employee & 62.2 & 69.6 & 33.3 & \\
\hline & Senior officer & 20.7 & 25.3 & 17.4 & \\
\hline \multirow[t]{3}{*}{ Importance of going to university } & Little and not important & 4.7 & 7.4 & 1.4 & 0.000 \\
\hline & Important & 40.0 & 61.7 & 20.3 & \\
\hline & Very important & 55.3 & 30.9 & 78.3 & \\
\hline
\end{tabular}

p: Significance level of Chi square test (comparison with F1).

${ }^{\S}$ Level of education: 1: End of compulsory studies; 2: Sixth form college diploma NVQ equivalent; 3: 12th grade diploma or A' level in Technical or professional studies; 4: University, college (higher education) diploma BTEC HND equivalent or first degree; 5: University, or specialised school diploma (higher education) Master or Doctorate / Engineer equivalent.

(AES) was positive and similar for the faculties in Luxembourg and Romania, and opposite for the faculty in Belgium, suggesting possible variations across faculties.

Firt, it should be noted that the students' age differed between the three faculties (youngest in Belgium and lodest in Luxembourg), and that students entered university one year younger in Belgium than in Luxembourg and Romania. The over-representation of women in social sciences is well known $[35,44]$. In Luxembourg, it has developed a policy of Life Long Learning among the population, in particular since the opening of the university in 2003.

The literature shows that QoL-psychological, QoLsocial relationships and QoL-environment differ greatly between countries (Table 5). Globally, in the three faculties we studied, the students' QoL-psychological was higher than, or similar to, that reported in other studies among university students. Students from F1 had a higher psychological QoL than did social sciences students in Brazil (74.4 vs 70.4) [35]. Students from F2 and F3 had intermediate values (respectively 63.7 and 64.8) close to that of Australian students (65.3) [32]. With regard to QoL-social relationships, the students from F1 and F2 had higher values than did students in Brazil (71.3) [35,44]. For QoL-environment, the students from F3 had a markedly lower value (56.3) than those from F1 and F2; but it was similar to that of Turkish students (52.1) [36]. This may be considered as satisfactory in the European context, given continuous changes in the demographic pattern of the student body, and difficult global economic circumstances, particularly for the Romanians [27].

Table 2 Comparison of QoL-psychological, academic employability skills (AES), QoL-social relationships and QoLenvironment between the faculties: sex-age adjusted means (SE)

\begin{tabular}{lcccc}
\hline & F1 (Luxembourg) N = 85 & F2 (Romania) N = 82 & F3 (Belgium) N = 69 & p-value \\
\hline QoL-psychological & $74.4(2.0)$ & $63.7(1.9)$ & $64.8(2.1)$ & 0.000 \\
QoL-social relationships & $75.3(2.6)$ & $69.0(2.5)$ & $65.2(2.8)$ & 0.020 \\
QoL-environment & $71.7(1.8)$ & $68.6(1.7)$ & $56.3(2.0)$ & 0.000 \\
Academic employability skills (AES) & $77.9(1.5)$ & $68.0(1.5)$ & $71.4(1.6)$ & 0.000 \\
\hline
\end{tabular}

$p$ = Significance level of type III test. 
Table 3 Relationships between QoL-psychological and socio-demographic characteristics, academic employability skills, QoL-social relationships and QoL-environment, for each faculty separately: Mean (SE) or Correlation coefficient

\begin{tabular}{|c|c|c|c|c|c|c|c|}
\hline & & \multicolumn{5}{|c|}{ WHOQoL-BREF-psychological [0-100] } & \\
\hline & & \multicolumn{2}{|c|}{ F1 (Luxembourg) } & \multirow{2}{*}{$\begin{array}{c}\text { F2 (Belgium) } \\
\text { Mean (SE) }\end{array}$} & \multicolumn{3}{|c|}{ F3 (Romania) } \\
\hline & & Mean (SE) & $\begin{array}{c}\text { p- } \\
\text { value }^{1}\end{array}$ & & $\begin{array}{c}\text { p- } \\
\text { value }^{1}\end{array}$ & Mean (SE) & $\begin{array}{c}\text { p- } \\
\text { value }^{1}\end{array}$ \\
\hline \multirow[t]{2}{*}{ Sex } & Female & $74.6(1.9)$ & .962 & $64.3(2.0)$ & .743 & $65.8(2.2)$ & .490 \\
\hline & Male & $74.7(3.3)$ & & $63.2(2.8)$ & & $61.0(6.6)$ & \\
\hline \multirow[t]{5}{*}{ Father's educational level ${ }^{2}$} & 1 & $78.3(4.7)$ & .263 & $52.3(5.6)$ & .125 & $67.9(5.1)$ & .045 \\
\hline & 2 & $74.3(3.0)$ & & $70.3(5.5)$ & & $65.3(4.5)$ & \\
\hline & 3 & $75.8(3.8)$ & & $66.4(4.7)$ & & $55.3(4.8)$ & \\
\hline & 4 & $78.1(4.3)$ & & $57.0(4.7)$ & & $71.8(6.9)$ & \\
\hline & 5 & $66.7(4.2)$ & & $63.2(2.9)$ & & $44.3(10.3)$ & \\
\hline \multirow[t]{5}{*}{ Mother's educational level ${ }^{2}$} & 1 & $80.0(4.0)$ & .091 & $56.0(5.6)$ & .540 & $67.1(5.2)$ & .451 \\
\hline & 2 & $72.6(3.4)$ & & $61.5(8.0)$ & & $64.5(4.9)$ & \\
\hline & 3 & $78.2(3.2)$ & & $66.4(4.4)$ & & $58.4(4.8)$ & \\
\hline & 4 & $71.3(3.9)$ & & $64.8(2.8)$ & & $73.3(8.9)$ & \\
\hline & 5 & $65.5(4.8)$ & & $60.0(4.2)$ & & $59.8(7.5)$ & \\
\hline \multirow[t]{3}{*}{ Father's professional status } & Manual worker & $79.0(3.9)$ & .236 & $62.2(4.6)$ & .932 & $64.8(4.2)$ & .686 \\
\hline & Employee & $75.1(2.5)$ & & $63.6(2.7)$ & & $64.1(5.2)$ & \\
\hline & Senior officer & $70.9(3.2)$ & & $64.2(2.7)$ & & $60.5(5.0)$ & \\
\hline \multirow[t]{3}{*}{ Mother's professional status } & Manual worker & $74.4(4.3)$ & .488 & $57.6(8.2)$ & .520 & $63.1(4.1)$ & .309 \\
\hline & Employee & $75.8(2.3)$ & & $63.1(2.0)$ & & $66.6(4.4)$ & \\
\hline & Senior officer & $70.8(3.8)$ & & $66.5(3.4)$ & & $57.0(5.8)$ & \\
\hline \multirow[t]{4}{*}{$\begin{array}{l}\text { Importance of going to } \\
\text { university }\end{array}$} & $\begin{array}{l}\text { Little and not } \\
\text { important }\end{array}$ & $70.7(7.3)$ & .192 & $55.9(6.1)$ & .381 & $64.6(17.9)$ & .734 \\
\hline & Important & $71.6(2.7)$ & & $64.7(2.1)$ & & $60.5(5.2)$ & \\
\hline & Very important & $77.5(2.4)$ & & $64.6(3.2)$ & & $64.7(4.2)$ & \\
\hline & & $\begin{array}{l}\text { correlation } \\
\text { coefficient }^{3}\end{array}$ & & $\begin{array}{l}\text { correlation } \\
\text { coefficient }^{3}\end{array}$ & & $\begin{array}{l}\text { correlation } \\
\text { coefficient }^{3}\end{array}$ & \\
\hline \multicolumn{2}{|l|}{ Age } & .023 & .839 & -.204 & .075 & .068 & .576 \\
\hline \multicolumn{2}{|l|}{ QoL-social relationships } & .595 & .000 & .458 & .000 & .629 & .000 \\
\hline \multicolumn{2}{|l|}{ QoL-environment } & .452 & .000 & .557 & .000 & .526 & .000 \\
\hline \multicolumn{2}{|c|}{ Academic Employability Skills (AES - 6 items) } & .288 & .009 & -.255 & .030 & .297 & .015 \\
\hline \multicolumn{2}{|c|}{ 1- Drafting/writing } & .084 & .456 & -.009 & .940 & .022 & .859 \\
\hline \multicolumn{2}{|c|}{ 2- Critical spirit/having sound judgment } & .103 & .361 & -.027 & .820 & .158 & .201 \\
\hline \multicolumn{2}{|c|}{ 3- Problem solving } & .303 & .006 & -.295 & .011 & .352 & .004 \\
\hline \multicolumn{2}{|c|}{ 4- Team working } & .316 & .004 & -.290 & .013 & .367 & .002 \\
\hline \multicolumn{2}{|c|}{5 - Supervision/direction of others } & .214 & .055 & -.166 & .160 & .309 & .011 \\
\hline \multicolumn{2}{|c|}{6 - Using new technologies } & .121 & .281 & -.116 & .330 & .028 & .819 \\
\hline
\end{tabular}

${ }^{1}$ Bivariate test adjusted for sex and age.

${ }^{2}$ Level of education: 1: End of compulsory studies; 2: Sixth form college diploma NVQ equivalent; 3: 12th grade diploma or A' level in Technical or professional studies; 4: University, college (higher education) diploma BTEC HND equivalent or first degree; 5: University, or specialised school diploma (higher education) Master or Doctorate / Engineer equivalent.

${ }^{3}$ For quantitative variables.

Our study showed that QoL-psychological was positively linked with academic skills and knowledge related to employability among social sciences students taking vocational/professional courses in Luxembourg and Romania. We found that this association could vary across faculties as it was negative among their general/ academically oriented Belgian counterparts. Two hypotheses may be raised: (1) The difference could be attributable to the two items of AES, namely problem solving and team working, which had the same link as between AES and QoL-psychological; it may suggest that the general/academically orientated training for the Belgians may include general aspects of social sciences and pay less attention to certain issues such as problem solving and team working than the other students receive with their vocational/professional orientation in 
Table 4 Relationships between QoL-psychological and Academic employability skills, QoL-social relationships and QoLenvironment (multiple regression)

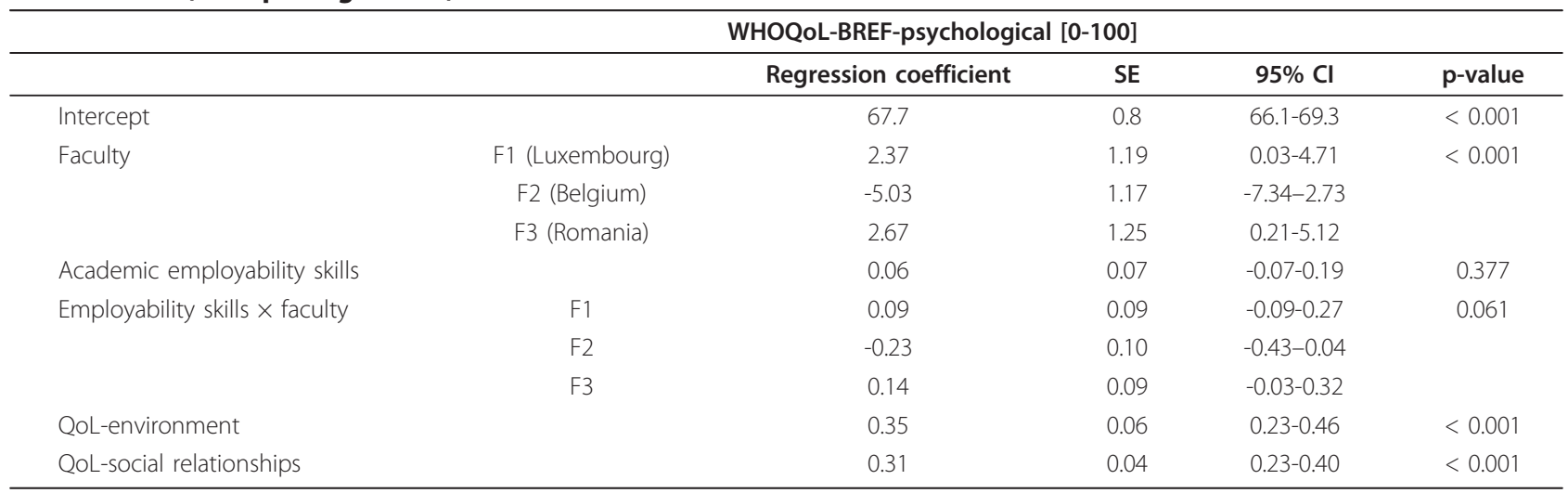

The socio-demographic factors are not shown because $p>0.10$.

Luxembourg and Romania; (2) The Belgians were younger and may be less satisfied with their AES as shown by their lower score (68.0 vs. 77.9 in Luxembourg, and 71.4 in Romania). Students with higher AES would find it insufficient to assure their professional future and this may impact on their QoL-psychological. Among the AES items, problem solving and team working may be more complex than writing and having sound judgment (which were not related to QoL-psychological at any faculty) so that younger age may impact on them. However, with recent reforms in European universities, students must, during their course, not only acquire the knowledge necessary to obtain the diploma they are preparing for, but also integrate the competences sought by employers. Our findings suggest that improving training in problem solving and team working for the general/academically orientated training would be helpful for the Belgians. Canadian research [23] highlighted some interesting points when comparing the academic employability skills of their students and post-graduates. It was observed that social sciences graduates who had worked for at least two years attained higher AES. The universities should thus provide students with high level AES and a good quality of life in the social relationships, environmental and psychological domains. The feeling of personal effectiveness is a major determinant of the process of belief necessary to work towards a potential occupation [45].

We found that, for the three faculties, the higher the psychological QoL, the higher QoL-social relationships and QoL-environment. When we compare our results with those in the literature, Luxembourg students seemed to have a comfortable QoL for all these domains. Conversely, Belgian students had values approaching those of Thai students, with a QoL-environment near to that of students in social sciences in Brazil. Romanian students had the lowest values, even lower than those of Thai students. In agreement with our results, a recent study among Turkish students showed that the better the mental health, the better the social relations, in particular romantic relationships [8]. Another recent study confirmed that the prevalence of psychiatric disorders among first-year students led to increased difficulty in adapting to university education. However, the cross-sectional study design prevents us from drawing conclusions about the direction of the link: poorly perceived adjustment to the academic environment may increase the risk of psychiatric disorders or psychiatric disorders may increase the difficulties in adjusting to the academic environment, or both may be

Table 5 WHOQOL-BREF domains among students: results from the literature

\begin{tabular}{|c|c|c|c|c|c|c|}
\hline Authors & Country & $\mathbf{N}$ & $\begin{array}{c}\text { Mean age or Group } \\
\text { age }\end{array}$ & $\begin{array}{l}\text { QoL- psychological M } \\
\text { (SD) }\end{array}$ & $\begin{array}{l}\text { QoL-social relationships } M \\
\text { (SD) }\end{array}$ & $\begin{array}{l}\text { QoL- environment M } \\
\text { (SD) }\end{array}$ \\
\hline $\begin{array}{c}\text { da Costa et al. } \\
\text { [34] }\end{array}$ & Brazil & 136 & $22.6 \pm 6.13$ & 70.4 (13.5) & $71.3(17.0)$ & $68.4(11.8)$ \\
\hline Eurich et al. [43] & Brazil & 67 & $21.2 \pm 4.3$ & $69.3(12.3)$ & $71.3(15.7)$ & $60.7(12.7)$ \\
\hline Hassed et al. [31] & Australia & 148 & $18.8 \pm 1.10$ & $65.6(16.1)$ & Unknown & Unknown \\
\hline Kalitesi et al. [35] & Turkey & 150 & 19 & $60.7(14.7)$ & $61.1(14.7)$ & $52.1(14.3)$ \\
\hline Li et al. [33] ${ }^{1}$ & Thailand & 407 & $20.5 \pm 1.2$ & $68.1(13.7)$ & $68.8(15)$ & $63.1(12.5)$ \\
\hline Wu and Yao [37] ${ }^{1}$ & Taïwan & 304 & $20.1 \pm 1.7$ & $54.4(15)$ & $60.6(16.9)$ & $58.8(12.5)$ \\
\hline
\end{tabular}

${ }^{1}$ Scores of this study were on a 0-20 scale, we transformed them to a 0-100 scale according to the calculation of the WHOQOL Group: (score - 4)*(100/16). 
caused by other factors not investigated here [19]. Although satisfaction with going to university was reported to be an important factor for academic achievement [25], our study failed to reveal an association between perceived importance of going to university and QoL-psychological at any of the three faculties.

This project is novel for several reasons. First, there are few investigations into QoL-psychological using the WHOQOL-BREF among students. Second, to our knowledge, no study has explored the link between psychological quality of life and academic employability skills. Third, social sciences and newly-registered students are not the populations assessed most frequently. We focused on newly-registered students because of the need to identify issues and to deal with problems as early as possible. This is important as it enables us to identify some problems and challenges related to transition periods. Every year, many students leave university without a diploma $[2,46]$. The beginning of university life is an important period of change for young adults in terms of interactions between individual bio-psychological characteristics and societal demands [4]. Young adulthood has great potential for personal growth or for failure that may impact on feelings of independence and control. The framework of our study responds to the new missions for universities to promote, for students, quality of life, employability and the participatory process [46].

\section{Some several limitations}

First, the survey was conducted among newly-registered volunteers and examined only one social sciences faculty per country; therefore, the results could not be generalized. Second, although the population is small, the participation rate of $66 \%$ is rather high for a web-based survey [47]. Unfortunately, no data are available with which to assess the participation bias. Third, a webbased self-administered questionnaire might lead to bias in terms of responses to questions [48]. However, the web-format WHOQOL-BREF is considered equivalent to the paper version [47], and the quality of the completed questionnaires was very high. Fourth, an advantage of the WHOQOL-BREF is that it has been used in cross-university surveys on mental health.

\section{Conclusion}

This study shows that QoL-psychological, academic employability skills, QoL-social relationships and QoLenvironment differed considerably between newly-registered students from the social sciences faculties in Luxembourg, Belgium and Romania. They were rather high among Luxembourg students and lower among the others. At all three faculties, QoL-psychological positively correlated with QoL-social relationships and QoL-environment, but the relationships between QoLpsychological and academic employability skills varied across faculties. It was positive for Luxembourg and Romanian students following vocational/professional orientated courses and negative for younger Belgian students in general/academically orientated training. Social status of parents defined by educational level and occupation did not play a role in this association. However, the academic employability skills and the quality of life were not at their best levels (score varying from 68.0 for Romanian, 71.4 for Belgian, and 77.9 for Luxembourg students on a $0-100$-point scale). Interventions can therefore be made to evaluate the difficulties and help students adapt to the university environment. In some universities, tutoring groups have been created to help students with their university work, working methods, interaction with other students, familiarity with academic requirements, stress reduction, achievement of feelings of control and autonomy and to promote appropriate coping strategies [45]. Efforts should also be devoted to improving pedagogic supervision of first-year students. Personal interviews can be used to advise on how to ensure that academic efforts correspond to professional projects and capacities [49]. Further studies are needed to explore these issues in other universities and for all undergraduate years, and especially among students who leave university without a diploma.

\section{Acknowledgements}

Thanks to: Jean-François Guillaume, Lecturer at the University of Liege, Belgium, Marie-Emmanuelle Amara (PhD student) and Véronique Pelt (scientific collaborator) who organised the surveys and conducted the statistical analyses with the participation of Etienne Le Bihan (statistician) from the University of Luxembourg, and all the volunteer students of the Faculty LSHASE, University of Luxembourg, the Department of Social Work, University of lasi, Romania, and the ISHS, University of Liege, Belgium without whom this research could not have been undertaken. Internal project (2008-2010) financed by the University of Luxembourg.

\section{Author details}

${ }^{1}$ INSIDE research unit, University of Luxembourg, Walferdange L-7201 Luxembourg. ${ }^{2}$ Department of Social Work, University Alexandru loan Cuza, lasi, R-700506 Romania. ${ }^{3}$ INSERM, Univ Paris-Sud U669, Univ Paris V UMRS0669, Paris F-75014 France.

\section{Authors' contributions}

MB conceived the protocol and tools of the survey, carried out the study and had the main responsibility for writing the manuscript.

II participated in conceiving and organising the survey.

$\mathrm{CN}$ participated in conceiving the statistical analyses and writing the manuscript.

The authors read and approved the final manuscript.

\section{Competing interests}

The authors declare that they have no competing interests.

Received: 8 February 2011 Accepted: 18 April 2011

Published: 18 April 2011 


\section{References}

1. European Commission: Key data of education in Europe 2005. Eurydice, Eurostat: Office for Official Publications of the European Community, Luxembourg: 2005, 390p.

2. Pech ME: Un tiers des étudiants de l'Organisation de coopération et de développement économiques (OCDE) finissent sans diplôme. [http:// www.lefigaro.fr/actualite-france/2010/09/13/01016-20100913ARTFIG00732un-tiers-des-etudiants-de---ocde-finissent-sans-diplome.php].

3. Adlaf EM, Gliksman L, Demers A, Newton-Taylor B: The prevalence of elevated psychological distress among Canadian undergraduates: findings from the 1998 Canadian Campus Survey. Journal American College Health 2001, 50:67-72

4. Arnett JJ: Emerging adulthood: a theory of development from the late teens through the twenties. American Psychologist 2000, 55:469-480.

5. Legleye S, Beck F, Peretti-Watel P, Chau N, Firdion JM: Suicidal ideation among French young adults: association with occupation, family, personal background and drug use. Journal of Affective Disorders 2010, 123:108-115.

6. Nock MK, Borges G, Bromet EJ, Alonso J, Angermeyer M, Beautrais A, Bruffaerts R, Chiu WT, de Girolamo G, Gluzman S, de Graaf R, Gureje O, Haro JM, Huang Y, Karam E, Kessler RC, Lepine JP, Levinson D, MedinaMora ME, Ono Y, Posada-Villa J, Williams D: Cross-national prevalence and risk factors for suicidal ideation, plans and attempts. British Journal of Psychiatry 2008, 192:98-105.

7. Roberts S, Golding J, Towell T, Reid S, Woodford S: Mental and physical health in students: the role of economic circumstances. British Journal Health Psychology 2000, 5(3):289-297.

8. Özdemir U, Tuncay T: Correlates of loneliness among university students. Child Adolescent Psychiatry Mental Health 2008, 2:29-39.

9. Finkelstein DM, Kubzansky LD, Goodman E: Social status, stress, and adolescent smoking. Journal of Adolescent Health 2006, 39(5):678-685.

10. Eisenberg D, Gollust SE, Golberstein E, Hefner JL: Prevalence and correlates of depression, anxiety, and suicidality among university students. American Journal of Orthopsychiatry 2007, 77:534-542.

11. American College Health Association: National American College Health Assessment. Spring, Group Data report. Journal American College Health 2006, 55:195-206.

12. Eisenberg D, Golberstein E, Gollust SE: Help-seeking and access to mental health care in a university student population. Medical Care 2007, 45:594-601.

13. El Ansari W, Stock C: Is the Health and Wellbeing of University Students Associated with their Academic Performance? Cross Sectional Findings from the United Kingdom. International Journal of Environmental and Research Public Health 2010, 7:509-527.

14. Tsouros AD, Dowding G, Thompson J, Dooris M: Health Promoting Universities Concept, Experience and Framework for Action. World Health Organization: Copenhagen, Denmark; 1998.

15. Spitz E, Costantini ML, Baumann M: [Adaptation and strategies of coping of the students in first academic year]. Revue Francophone Stress Trauma 2007, 7(3):217-225

16. Niemi SM, Levoska S, Rekola KE, Keinanen-Kiukaanniemi S: Neck and shoulder symptoms of high school students and associated psychosocial factors. Journal of Adolescent Health 1997, 20(3):238-242.

17. Craig TKJ: Students' health needs: problems and responses. The Psychiatrist 2004, 28:69-70.

18. Vaez $M$, Kristenson $M$, Laflamme L: Perceived quality of life and self-rated health among first-year university students, a comparison with their working peers. Social Indicators Research 2004, 68(2):221-234.

19. Patel V, Flisher AJ, Hetrick S, McGorry P: Mental health of young people: a global public-health challenge. Lancet 2007, 369:1302-1313.

20. Pelt $\mathrm{V}$, Baumann M: How universities can assess employability skills? In The Bachelor: Changes in Performance and Quality of studying? Empirical Evidence in International Comparison. Edited by: T. Bargel, M. Schmidt, H. Bargel. Ed. University of Konstanz; 2010:66-82.

21. FRERET: Studying in a changing university: the works of the UNI 21 research group. 2010 [http://www.freref.eu/index.php?lang=en].

22. European Council: The Bologna Process - Towards the European Higher Education Area. 2009 [http://ec.europa.eu/education/higher-education/ doc1290_en.htm].

23. Lin Z, Sweet R, Anisef P, Schuetze H: Consequences and policy implications for university students who have chosen liberal or vocational education. Labour market outcomes and employability skills. Human Resources Development Canada; 2000 [http://www.rhdsc.gc.ca/fr/ sm/ps/rhdc/rpc/publications/recherche/2000-000184/page00.shtml].

24. Steptoe A, Wardle J: Health behaviour, risk awareness and emotional well-being in students from Eastern Europe and Western Europe. Socia Sciences and Medicine 2001, 53(12):1621-1630.

25. Wardle J, Steptoe A, Gulis G, Sartory G, Sek H, Todorova I, Vogele C, Ziarko M: Depression, perceived control, and life satisfaction in university students from Central-Eastern and Western Europe. International Journal Behavioral Medicine 2004, 11(1):27-36.

26. Skevington SM, Lotfy M, O' Connell KA: The World Health Organization's WHOQOL-BREF quality of life assessment: psychometric properties and results of the international field trial. Areport from the WHOQOL group. Quality Life Research 2004, 13(2):299-310.

27. European Foundation for the improvement of living and working conditions: How are you? Quality of Live in Europe. 2010 [http://www. eurofound.europa.eu/publications/focusform.htm], Focus issue.

28. Stecker T: Well-being in an academic environment. Medical Education 2004, 38:465-478.

29. WHO Europe: European Pact for mental health and Well-being. EU Highlevel conference "Together for mental health and wellbeing": Brussels; 2008 [http://ec.europa.eu/health/ph_determinants/life_style/mental/ mental_health_fr.htm].

30. Mikolajczyk R, Brzoska P, Maier C, Ottova V, Meier S, Dudziak U, llieva S, El Ansari W: Factors associated with self-rated health status in university students; a cross-sectional study in three European countries. BMC Public Health 2008, 8:215.

31. Kramer A, Prufer-Kramer L, Sock C, Tshiananga JT: Differences in health determinants between international and domestic students at a German University. Journal American College Health 2004, 53(3):127-132.

32. Hassed C, de Lisle S, Sullivan G, Pier C: Enhancing the health of medical students: outcomes of an integrated mindfulness and lifestyle program. Advance Health Sciences Education Theory Practice 2009, 14:387-398.

33. Yao G, Wu CH, Yang CT: Examining the content validity of the WHOQOLBREF from respondents' perspective by quantitative methods. Social Indicators Research 2008, 85:483-498.

34. Li K, Kay NS, Nokkaew N: The performance of the World Health Organization's WHOQOL-BREF in assessing the quality of life of Thai College Students. Social Indicators Research 2009, 90:489-501.

35. da Costa CC, de Bastiani M, Geyer JG, Calvetti PU, Muller MC, Andreoli de Maoraes AL: Qualidade de vida e bem-estar espiritual em universitarios de Psicologia. Psicologia Estudo 2008, 13(2):249-255.

36. Kalitesi Y, Destek S, Ag Ve Yalnizlik S, lliskiler A: Relationships between quality of life, perceived social support, social network, and loneliness in a Turkish sample. Yeni Symposium 2004, 42(1):20-27.

37. Zimmermann J, Eisemann MR, Fleck M: Is parental rearing an associated factor of quality of life in adulthood? Quality Life Research 2008 17:249-255.

38. Wu CH, Yao G: Examining the Relationship between global and domain measures of quality of life by three factor structure models. Social Indicators Research 2007, 840:189-202.

39. Angermeyer MC, Kilian R, Matschinger H: WHOQOL-100 und WHOQOLBREF. Handbuch fur die Deutschsprachige Version der WHO Instrumente zur Erfassung von Lebensqualität. Hogrefe, Göttingen; 2000.

40. Leplège A, Réveillère $C$, Ecosse E, Caria A, Rivière H: [Psychometric properties of a new instrument of evaluation of the quality of life, the WHOQOL-26, starting from a population of neuro-muscular patients]. Encephale 2000, 26:13-22.

41. The World Health Organization: Quality of Life (WHOQOL)-BREF. World Health Organisation; Geneva; 2004.

42. Chen KH, Wu CH, Yao G: Applicability of the WHOQoL-BREF on early adolescence. Social Indicators Research 2006, 79:215-234.

43. Baumann M, Aïach P: Promotion of health and reduction of the social inequalities of health in Europe: complex problems. In Handbook of the social and educational intervention. Edited by: Willems, H. Funds of Social European, University of Luxembourg, INSIDE, Ed. Saint Paul, Luxembourg; 2009:1195-1206.

44. Verger P, Guagliardo V, Gilbert F, Rouillon F, Kovess-Masfety V: Psychiatric disorders in students in six French universities: 12-month prevalence, comorbidity, impairment and help-seeking. Social Psychiatry and Psychiatric Epidemiology 2010, 45:189-199. 
45. Eurich RB, Kluthcovsky AGC: Evaluation of quality of life of undergraduate nursing students from first and fourth years: The influence of sociodemographic variables. Revista Psiquatria do Rio Grande do Sul 2008, 30(3):211-220.

46. Colquitt JA, Le Pine JA: Toward and integrative theory of training motivation: A meta-analytic path analysis of 20 years of research. Journal of Applied Psychology 2000, 85(5):678-707.

47. Chen WC, Wang JD, Hwang JS, Chen CC, Wu CH, Yao G: Can the WebForm WHOQOL-BREF be an alternative to the Paper-Form? Social Indicators Research 2009, 94(1):97-114.

48. Brener ND, Kann L, Kinchen SA, Grunbaum JA, Whalen L, Eaton D, Hawkins J, Ross JG: Methodology of the youth risk behavior surveillance system. MMWR Recommendation and Report 2004, 24(53):1-13, RR-12.

49. Gammon J, Morgan-Samuel H: A study to ascertain the effect of structured student tutorial support on student stress, self-esteem and coping. Nurse Education Practice 2005, 5:161-171.

Pre-publication history

The pre-publication history for this paper can be accessed here: http://www.biomedcentral.com/1471-244X/11/63/prepub

doi:10.1186/1471-244X-11-63

Cite this article as: Baumann et al.: Psychological quality of life and its association with academic employability skills among newly-registered students from three European faculties. BMC Psychiatry 2011 11:63.

\section{Submit your next manuscript to BioMed Central} and take full advantage of:

- Convenient online submission

- Thorough peer review

- No space constraints or color figure charges

- Immediate publication on acceptance

- Inclusion in PubMed, CAS, Scopus and Google Scholar

- Research which is freely available for redistribution

Submit your manuscript at www.biomedcentral.com/submit 